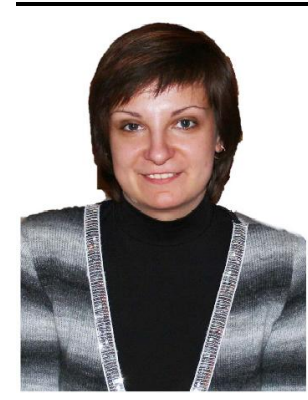

УДК 338.436 .33

https://doi.org/10.47612/978-985-7149-55-1-2020-220-221

Елена Трифонова, кандидат экономических наук, доцент, старший научный сотрудник

Институт аграрных проблем Российской академии наук, г. Саратов, Россия

\title{
Проблема повышения \\ конкурентоспособности продукции пищевой \\ промышленности России с учетом современных тенденций международной интеграции
}

Одним из приоритетных направлений развития российского агропромышленного комплекса является производство конкурентоспособной продукции пищевой промышленности. В сложившихся современных условиях, благодаря реализации политики импортозамещения, Россия достигла, а в некоторых случаях даже превзошла пороговые значения Доктрины продовольственной безопасности страны по ряду ключевых продуктов питания. В связи с этим за период с 2013 по 2018 г. снизился импорт продовольственных товаров на 31,2 \% [1].

На сегодняшний день экспорт продовольственных товаров и сельхозсырья составляет не более $6 \%$ от общей суммы всех вывозимых товаров за пределы Российской Федерации. Удельная доля импорта аналогичной товарной группы зафиксирована на уровне 12-13\%. При этом в стоимостном выражении наблюдается рост как экспорта, так и импорта продовольствия и сельхозсырья, но с разными темпами прироста. Если импорт в 2018 г. по сравнению с 2016 г. возрос на 18,6\%, то экспорт - на 45,9\% (рис.). Однако основной вклад в увеличение экспорта внес все же вывоз сельхозсырья, а не готовой продукции пищевой промышленности.

В условиях членства России во Всемирной торговой организации сложилась ситуация, при которой способность отечественной пищевой продукции выдерживать конкуренцию с импортными аналогами приобрела первостепенное значение. До недавнего времени производители продовольственных товаров не уделяли достаточного внимания повышению конкурентоспособности выпускаемой продукции. Данная ситуация во многом была связана с объективными причинами состояния предприятий отрасли: выраженная сезонность загрузки мощностей; высокий уровень износа производственных мощностей, их недозагруженность; морально устаревшие технологии производства; зависимость многих отраслей от импортного сырья и т. п. Однако сегодняшние условия стратегического прорыва в функционировании и положении на рынке многих крупных предприятий отрасли диктуют необходимость повышения конкурентоспособности выпускаемой продукции по целому ряду параметров. Более того, в последнее время существенно улучшилось качество отечественных продуктов, при этом в отношении многих продуктов можно утверждать, что их качество превзошло импортные аналоги.

Повышение конкурентоспособности как продукции пищевой промышленности, так и всего предприятия в долгосрочной перспективе может быть основано только на определенных мерах, требующих существенных финансовых вложений и характеризующихся временным лагом в получении отдачи от проводимых мероприятий. К числу подобных мер можно отнести в первую очередь внедрение технологических, организационных

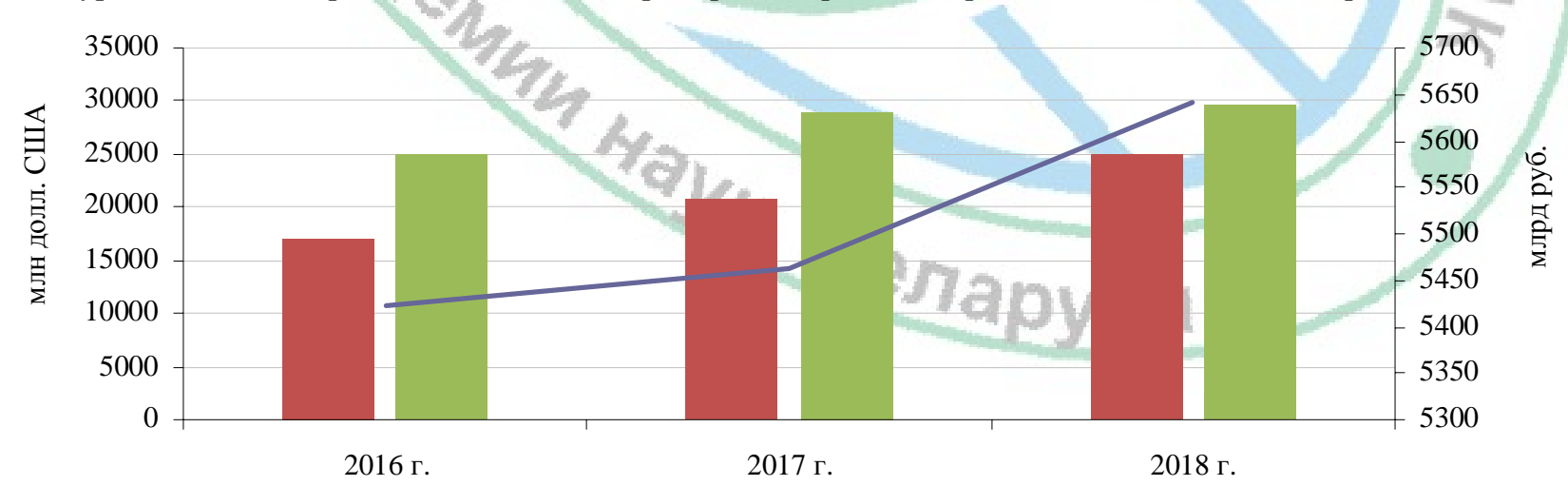

Экспорт продовольственных товаров и сельскохозяйственного сырья (кроме текстильного), млн долл. США

Импорт продовольственных товаров и сельскохозяйственного сырья (кроме текстильного), млн долл. США

- Объем отгруженных товаров собственного производства, выполненных работ и услуг собственными силами при производстве пищевых продуктов, млрд руб.

Рис. Динамика соотношения показателей экспорта - импорта и производства продукции пищевой промышленности Российской Федерации 
и маркетинговых инноваций, сопряженных с принципиальным улучшением качественных характеристик выпускаемой продукции.

В современных условиях глобализации рыночного пространства, а также его информатизации и всевозрастающей роли маркетинговых технологий пропаганды определенного стиля потребления становится недальновидно игнорировать усиление влияния факторов, выходящих за рамки количественного учета и анализа состояния локально выделенного рынка. Помимо классического подхода к анализу показателей, характеризующих спрос и предложение на рынке товара, а также показателей, отражающих затратность и эффективность производства, необходим более специфичный подход к разработке стратегии развития предприятий, учитывающий подобные нестандартные факторы и глобальные рыночные тенденции, которые порой не поддаются количественному измерению. Особенно это важно в ситуации, когда планируются принципиальные изменения в тенденциях как внутреннего потребления, так и увеличения экспорта продовольствия.

- Особое значение данная проблема приобретает в связи с разработанным Минпромторгом России национальным проектом «Международная кооперация и экспорт», а именно с одним из пяти проектов национального уровня в структуре национального проекта «Экспорт продукции АПК». Его целью является разработка мер, позволяющих нарастить экспорт сельскохозяйственной продукции в два раза до 2024 г., а именно до 45 млрд долл. США за счет создания новой товарной массы, в том числе с высокой добавленной стоимостью. По нашей оценке, для достижения поставленной цели ежегодный прирост производства продукции отрасли должен увеличиться с существующих 4-5\% до 10-12\% [2]. Этого невозможно добиться без принципиальных мер по повышению конкурентоспособности продукции пищевой отрасли АПК.

Одним из элементов совокупности мер, направленных на принципиальный рост производства в пищевой отрасли, является внедрение инноваций в той или иной форме. Однако далеко не все представители бизнеса способны самостоятельно привлечь ресурсы для осуществления поставленных целей. Это представляется возможным только при условии активного привлечения инвестиций, а также при разумной государственной поддержке предприятий пищевой промышленности, допустимой правилами ВТО.

Стоит отметить, что за последние пять лет существенно увеличились объемы государственной поддержки АПК в целом [1]. На реализацию Государственной программы развития сельского хозяйства и регулирования рынков сельскохозяйственной продукции, сырья и продовольствия на период до 2025 года было выделено 197,7 млрд руб. в 2013 г. против запланированных 307,9 млрд руб. в 2019 г. Кроме того, в российской экономике отчетливо наметилась тенденция наращивания государством своего присутствия в экономике. По данным Федеральной антимонопольной службы, вклад госкомпаний в ВВП России вырос с 35 \% в 2005 г. до 70 \% в 2015 г. [3].

На сегодняшний день в рамках применяемого механизма госрегулирования экономики в качестве реально существующих, хорошо зарекомендовавших себя на практике инструментов поддержки предприятий пищевой и перерабатывающей промышленности можно выделить льготное кредитование и предоставление единой субсидии. При этом возникает вполне оправданная потребность в разработке действенной методики распределения государственных финансовых ресурсов между предприятиями пищевой промышленности с учетом как реальных потребностей субъектов хозяйствования, так и региональных особенностей отрасли. В качестве альтернативы существующим подходам нами предложена авторская методика ранжирования регионов по уровню потенциальных возможностей наращивания конкурентных преимуществ продукции пищевой промышленности, базирующаяся на расчете и определении пороговых значений общего интегрального показателя [4].

Разработка и совершенствование экономического механизма повышения конкурентоспособности продукции российской пишевой промышленности неразрывно связаны со спецификой отраслей переработки и их региональными особенностями. Необходим единый дифференцированный регионально-отраслевой подход к поддержке бизнес-проектов в агропромышленном комплексе, основанный на обосновании формы государственной поддержки региональной пищевой промышленности, а также варианта участия государства в финансировании перспективных направлений бизнеса.

\section{Список использованных источников}

1. За последние 5 лет Россия сократила импорт продовольствия на треть [Электронный ресурс] // Министерство сельского хозяйства Российской Федерации. Режим доступа: http://mcx.ru/press-service/news/zaposlednie-5-let-rossiya-sokratila-import-prodovolstviya-natret/. - Дата доступа: 05.08.2020.

2. Трифонова, Е. Н. Оценка перспектив реализации федерального проекта «Экспорт продукции АПК» с учетом существующих тенденций развития пищевой промышленности РФ [Электронный ресурс] / Е. Н. Трифонова // Региональные агросистемы: экономика и социология: ежегодник. - Саратов : ИАгПРАН. - 2019. № 3. - С. 64-69. - Режим доступа: http://www.iagpran.ru. Дата дступа: 07.08.2020.

3. Государство и госкомпании контролируют $70 \%$ российской экономики [Электронный ресурс] // Ведомости. - 2016. - 29 сент. - Режим доступа: https://www. vedomosti. ru/ economics/articles/2016/09/29/658959goskompanii-kontroliruyut-ekonomiki. - Дата доступа: 03.08.2020.

4. Трифонова, Е. Н. Совершенствование механизмов господдержки предприятий пищевой промышленности регионов РФ с целью повышения конкурентоспособности продукции [Электронный ресурс] / Е. Н. Трифонова // Региональные агросистемы: экономика и социология: ежегодник. - Саратов : ИАгП РАН. - 2019. - № 4. С. 109-118. - Режим доступа: http://iagpran.ru/journal.php? tid=802. - Дата доступа: 02.08.2020.

Материал поступил 09.08.2020 г. 